\title{
Vendor Rating Using Analytical Hierarchical Process - Insights from Indian Engineering Construction Industry
}

\author{
Vani Haridasan ${ }^{1}$, Sudharsan $\mathbf{M}^{2}$ \\ ${ }^{1}$ Associate Professor \\ SSN School of Management \\ Kalavakkam, Chennai - 603110 \\ Tamil Nadu \\ ${ }^{2}$ Student, SSN School of Management
}

\begin{abstract}
:
Vendor Evaluation and Selection is one of the most critical activities of purchasing management in supply chain. It is a complex problem involving qualitative and quantitative multi-criteria. A trade-off between these tangible and intangible factors is essential in selecting the best supplier. This paper aims to develop a vendor rating system for Engineering Construction Industry where there is a huge involvement in the purchases of Pipes (like Ductile Iron, Mild Steel, HDPE, RCC, PVC), Pumps, Electrical items (like Panels, PLC, Motors, Generators) and Mechanical items for Water \& Effluent Treatment Projects. The conventional method is less accurate in ranking the vendors as a result of greater amount of subjectivity.This paper focuses on developing a Vendor Rating System using AHP methodology to choose the best suppliers in such a way to reduce the time taken for the selection process.
\end{abstract}

Keywords: Vendor rating, Supplier Selection, Multi-Criteria Decision Making, Analytical Hierarchical Processing.

\section{Introduction}

Infrastructure sector, a key driver for the Indian economy is highly responsible for propelling the country's overall development and enjoys intense focus from Government for initiating policies that would ensure time-bound creation of world class infrastructure in the country.

Infrastructure sector includes power, bridges, dams, roads and urban infrastructure development. In 2016, India jumped 19 places in World Bank's Logistics Performance Index (LPI) to rank 35th amongst 160 countries.

One of the key sectors is the construction Industry which contributes to 10 per cent of India's GDP. The construction industry is climbing up the growth ladder, with 100 per cent FDI and an expected investment of $\$ 650$ billion in the coming 20 years.

In general, construction industry can be classified under 3 major categories; viz, buildings, infrastructure and industrial. Building construction is further divided into Residential and Non-residential (commercial / institutional).Non-residential, which has three sub-sectors; namely, Heavy industrial construction, Institutional and commercial construction. Heavy Industrial Construction involves building huge industrial facilities like power plants, refineries, nuclear plants, mines and oil sands installations. Institutional and commercial construction refers to the building of structures such as high-rise condos and office towers, stadiums, schools, hospitals, malls, libraries, art galleries and museums.

Engineering Construction provides the core infrastructure and installation of the essential services that keep the community running smoothly. It involves building the bridges, highways, roads and mass transit systems that allow people to travel safely in their everyday lives. Engineering Construction involves installing essential services like water treatment systems that keep communities healthy, and power and communication lines that support economic growth. The Engineering Construction sector improves our quality of life. 


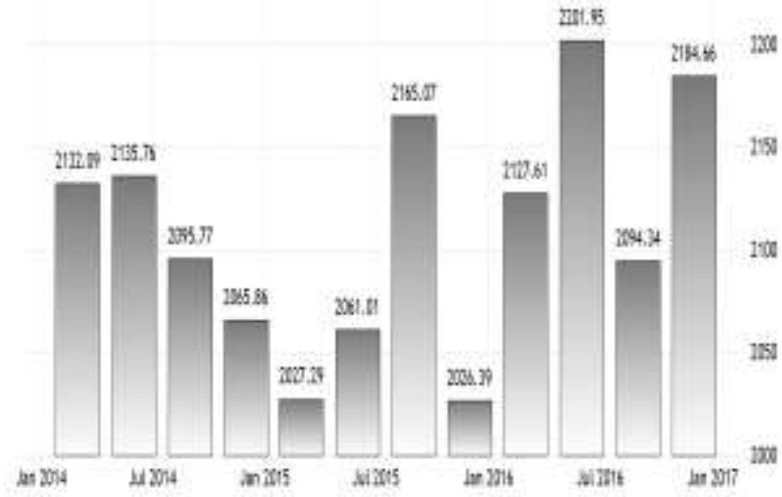

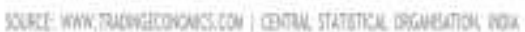

Fig. 1 India GDP from Construction Industry

1. Supply Chain Management

The Supply chain has been defined as "a network of facilities that procure raw materials, transform them into intermediate goods and then final products, and deliver the products to customers through a distribution system". (Lee and Billington, 1992)

SCM involves planning, organizing, directing \& controlling flows of materials. It begins with raw materials, continues through internal operations and ends with distribution of finished goods. The main objective is to Maximize value \& Minimise waste.

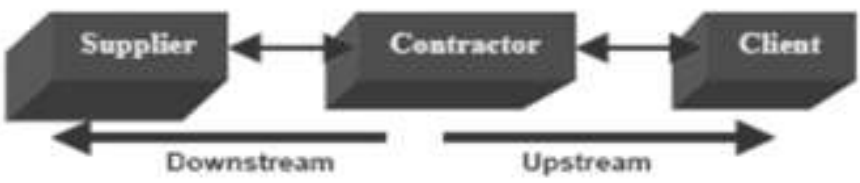

Fig. 2 Flow in a Supply Chain

2. Differences between Production and Construction Industry

\begin{tabular}{|c|c|}
\hline PRODUCTION INDESTRY & CONSTRLCTION INDUSTRY \\
\hline Products are all standardized. & $\begin{array}{l}\text { Each project is unique in conient \& nantre } \\
\text { of exectution. }\end{array}$ \\
\hline $\begin{array}{l}\text { Manufiacturing process are permaneut. } \\
\text { Long recu plaming is possible }\end{array}$ & Site Locations are transient and tempotary. \\
\hline $\begin{array}{l}\text { Increase in raw materials cost conld be } \\
\text { passed on to customers turough increase } \\
\text { in sales price of finished products }\end{array}$ & $\begin{array}{l}\text { Cost is pre-determined at start of project } \\
\text { and care has to be tnken to ensture that } \\
\text { provisions are not ovemum }\end{array}$ \\
\hline
\end{tabular}

\section{Supply Chain Responsibilities in a Construction Industry}

In addition to streamlining the operational aspects in a supply chain, there are some complex responsibilities in the downstream Supply Chain in a Construction Industry.
- Global Supply Chain Management

- Optimization of Materials cost

- Finalization of Rate agreement/ MOU for Volume based items

- Tendering Support

- Execute subcontracts where material is involved along with services

- Co-ordination with all stakeholders for smooth flow of Materials

- MIS reporting

- Training

4. Broad Classification of Materials:

- Civil and Structural Items

- Pipes, Valves, Pumps etc.

- Electro - Mechanical Items

\section{Pipes:}

DI Pipes:

- Ductile Iron pipe is widely used for water supply pipelines, sewage pipelines, industrial water pipelines, as well as agricultural water pipelines.

- Ductile iron pipe is highly accepted because of its excellent strength, durability and laying workability.

- Ductile iron is improved gray cast iron which is superior in mechanical property yet stronger than steel.

- Magnesium or its alloy is added to molten iron to spheroidize graphite.

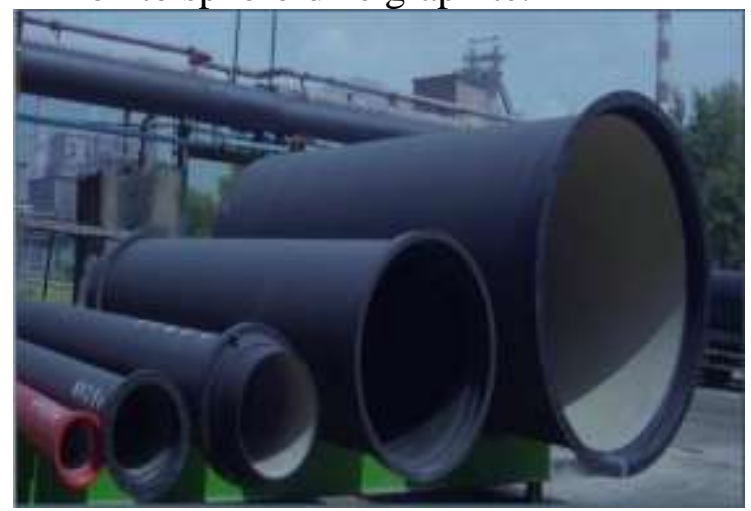

Fig. 3Ductile Iron Pipes

MS Pipes: 
- Mild Steel (MS) pipes are manufactured using low carbon (less than $0.25 \%$ ) steel. Due to low carbon content the pipes do not harden and are easy to use.

- As MS Pipes are made from mild steel they can easily be welded and formed in various shapes and sizes for pipelining and tubing purposes.

- These are generally used for drinking water supply i.e. Plumbing, Firefighting, HVAC but can also be used in various other Industrial and Engineering applications.

- These pipes are usually coated with other metals/paints/varnish etc., to prevent it from rusting but extra care should be taken to prevent it under extreme conditions

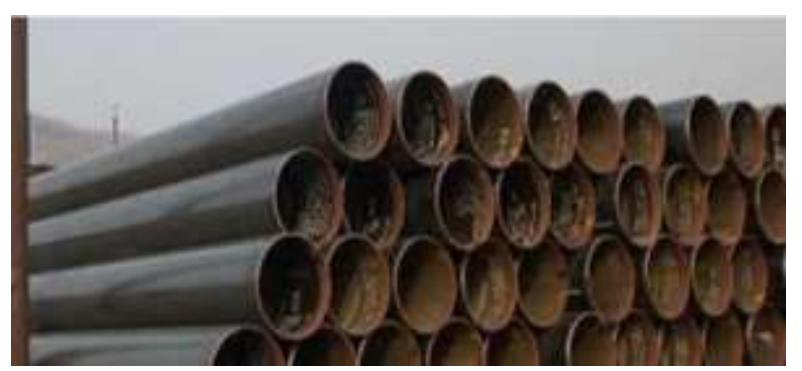

\section{HDPE Pipes:}

- Pipes made from Polyethylene (PE) is a costeffective answer for a number of piping problems in Metropolitan, Municipal, Industrial, Underwater, Mining, Landfill Gas extraction, Cable duct and agricultural applications.

- It has been tested and proven effective for underground, above ground, surface, under water as well as floating pipe applications.

- Polyethylene pipes both High Density (HDPE) and Medium Density (MDPE) can carry potable water, wastewater, slurries, chemicals, hazardous wastes, cables and compressed gases as well as oils.

- Polyethylene pipes have a long and successful service experience to the gas oil, mining and water utility industries.

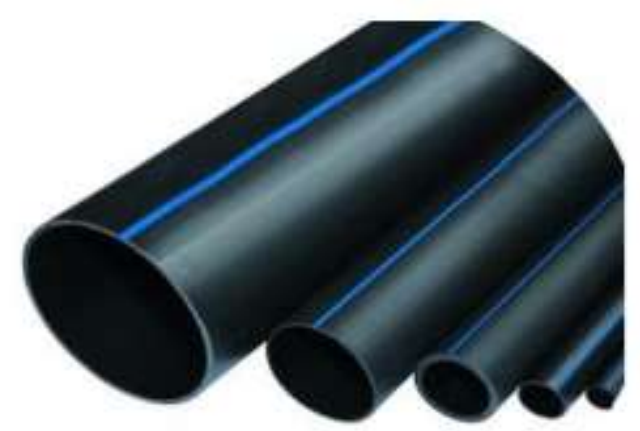

Fig. 5High Density Polyethylene Pipes

\section{Procurement Methods:}

- Quotations \& Negotiations

- Reverse Auctions

- Rate Contracts

- Strategic Tie Ups

\section{Procurement Process:}

1. Invite quotations from reputed firms

2. Comparison of offers based on basic price, freight $\&$ insurance, taxes and levies

3. Payment terms, Delivery period, Guarantee etc.,

4. Vendor reputation - (reliability, technical capabilities, Logistics, Availability, after-sales service etc.) and ranking.

5. Short listing for better negotiation terms

6. Seek order acknowledgement

The current method of supplier selection is conventional where the process starts with inviting quotations, followed by short listing the suppliers based on price alone. But there is a compelling need to assess and monitor supplier performance with a view to rewarding suppliers who meet expectations with on-going and future supply relationships; improve the performance of Supply Chain Management department by providing a more reliable and precise vendor rating practices; provide accurate feedback to suppliers to highlight their strengths as well as their weaknesses and establish continuous review standards for vendors, thus ensuring continuous improvement of vendor performance.

This paper aims to develop a vendor rating system for Engineering Construction Industry where there is a huge involvement in the purchases of Pipes (like Ductile Iron, Mild Steel, HDPE, RCC, PVC), Pumps, Electrical items (like Panels, PLC, Motors, Generators) and Mechanical items for Water \& Effluent Treatment Projects. The conventional method is less accurate in ranking the vendors as a result of greater amount of subjectivity. This paper focuses on developing a Vendor Rating System using AHP methodology to choose the best suppliers in such a way to reduce the time taken for the selection process.

\section{Literature Review}

Vendor Evaluation (Kurian John et al., 2013) is a system for recording and ranking the performance of a supplier in terms of a variety of issues, which may include delivery performance and the quality of the items. A process of vendor rating is essential for 
effective purchasing. The authors developed a vendor evaluation and rating system, which incorporates the evaluation and rating criteria of suppliers of valves, which was purchased through the equipment spares and supplier section of the purchase department.

S.D. Pohekar et al (2003) describes that MultiCriteria Decision Making (MCDM) techniques are gaining popularity in sustainable energy management. The techniques provide solutions to the problems involving conflicting and multiple objectives. Several methods based on weighted averages, priority setting, outranking, fuzzy principles and their combinations are employed for energy planning decisions. A review of more than 90 published papers is presented to analyze the applicability of various methods discussed. A classification on application areas and the year of application is presented to highlight the trends. It is observed that Analytical Hierarchy Process is the most popular technique followed by outranking techniques PROMETHEE and ELECTRE. Validation of results with multiple methods, development of interactive decision support systems and application of fuzzy methods to tackle uncertainties in the data is observed in the published literature.

Huang et al (2007) explains that as firms are increasingly becoming outsourcing oriented, supplier selection has become a major strategic decision for Original Equipment Manufacturers (OEMs). While strategic thinking cannot provide quantitative solutions, a mathematically optimal solution has no meaning if it does not match a firm's business strategy. Therefore, there is a need to integrate strategic thinking with quantitative optimization in order to make sound and effective decisions on supplier selection. The authors present an integration mechanism in terms of a set of comprehensive and configurable metrics arranged hierarchically that takes into account product type, supplier type, and OEM/supplier integration level. Based on a firm's business strategy, the management configures an appropriate set of metrics used to measure supplier performance. An optimal supplier selection decision is then made based on this chosen set of metrics, achieving a strategic fit between the firm's business model and its supply chain strategy.

FarzadTahriri et al., (2008) in their research represented the systematic identification of the important criteria for supplier selection process. The authors exhibited the application of development of a multi-criteria decision model for evaluation and selection of suppliers with proposed AHP model, which by scoring the performance of suppliers is able to reduce the time taken to select a vendor. In their paper, an AHP-based supplier selection model is formulated and then applied to a real case study for a steel manufacturing company in Malaysia. The use of the proposed model indicates that it can be applied to improve and assist decision making to resolve the supplier selection problem in choosing the optimal supplier combination.

In today's highly competitive and interrelated manufacturing environment, effective selection of suppliers is very important to the success of manufacturing firm (Krishna Veni et al., 2012). Evaluation and selection of the best among the offers provided by the various suppliers is a complex problem, that takes into account both tangible and intangible criteria's. The authors consider supplier selection as a multi-criterion decision problem. Data Envelopment Analysis (DEA) is used to generate local weights of alternatives from pairwise comparison judgement matrices used in the Analytical Hierarchy Process (AHP). The local weights generated by DEA are aggregated using AHP Procedure.

\section{Vendor Rating Using Analytical Hierarchical Process}

The proposed system for Vendor Rating is based on using Analytical Hierarchical Process (AHP) for evaluating and ranking vendors. This system is proposed to minimize subjectivity in assigning weights for the criteria and also improve the efficiency of the decision-making approach.

The conventional approach has some flaws which includes- no specific guideline for assigning the weights for the criterion; high amount of vendor bias; the rating is performed by a single person who was in charge of ordering a single type of pipe and he might not have extensive input information about the qualitative criterion of vendors dealing in other type of pipes.

The Analytical Hierarchical Process (AHP), introduced by Thomas Saaty (1980), is an effective tool for dealing with complex decision making, and may aid the decision maker to set priorities and 
make the best decision. By reducing complex decisions to a series of pairwise comparisons, and then synthesizing the results, the AHP helps to capture both subjective and objective aspects of a decision. In addition, the AHP incorporates a useful technique for checking the consistency of the decision maker's evaluations, thus reducing the bias in the decision-making process. AHP considers a set of evaluation criteria, and a set of alternative options among which the best decision is to be made. It is important to note that, since some of the criteria could be contrasting, it is not true in general that the best option is the one which optimizes each single criterion, rather the one which achieves the most suitable trade-off among the different criteria.

To initiate the AHP process, we identify the following three step procedure

- The decision-making problem is decomposed into a hierarchy structure.

- Pair wise comparisons are made and establish priorities among the elements in the hierarchy.

- Synthesise judgments (to obtain the set of overall or weights for achieving your goal).

- Evaluate and check the consistency of judgements.

\section{$\underline{\text { Step } 1 \text { - Hierarchy Structure }}$}

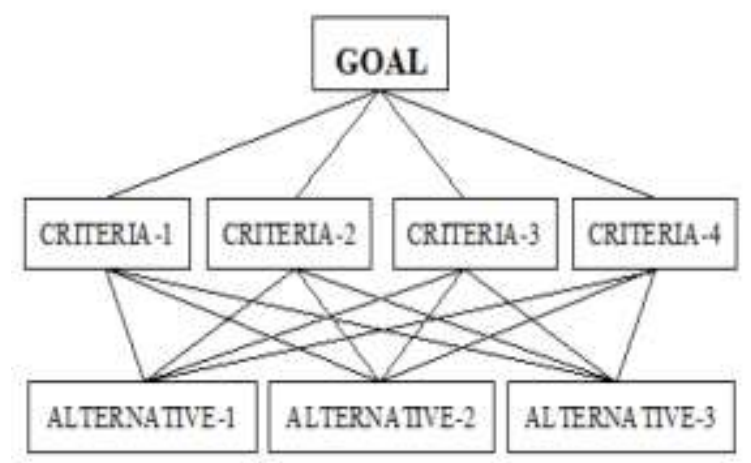

The hierarchy structure starts with the ultimate goal. To achieve this goal, various criteria are developed. They are linked to the alternatives. In the proposed system, the main goal is to develop a system to rate the vendors. The multiple criteria used for decisionmaking are quality, on-time delivery, price, responsiveness and credit period. The vendors are used for the decision alternatives.

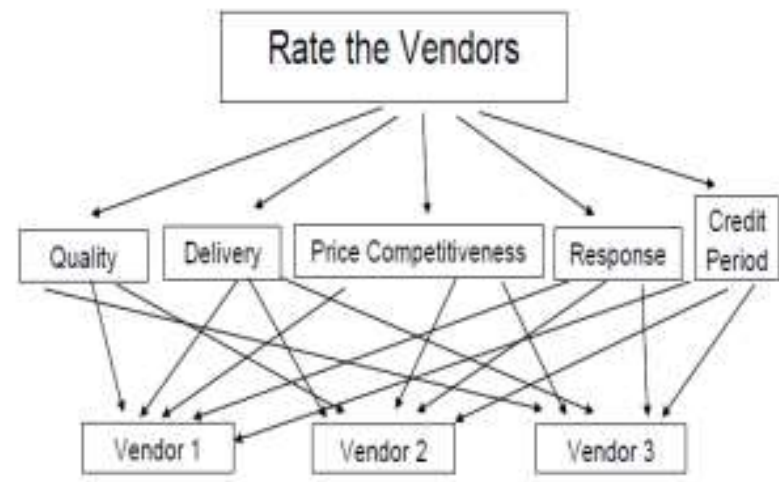

$\underline{\text { Step } 2 \text { - Pair-wise Comparisons: }}$

Pair-wise comparisons are made to establish priorities among the elements in the hierarchy. For pair-wise comparisons, each alternative (or Vendor) is matched head-to-head (one-on-one) with each of the other alternatives (Vendors) on the basis of selection criteria. The table below shows the pairwise comparison of vendors based on Quality. There are four vendors, V1, V2, V3 and V4 under consideration for DI pipes.

A pair-wise comparison among selection criteria is done to determine the relative importance (weights) among them. Then vendors are compared on each selection criteria separately to obtain the scores. The pairwise comparison for DI pipes based on Quality is given below.

Pairwise Comparison of DI Vendors based on Quality

\begin{tabular}{|c|c|c|c|c|}
\hline & $V_{1}$ & $V_{2}$ & $\sqrt{3}$ & $\mathrm{V4}$ \\
\hline VI & I & 1 & 3 & 5 \\
\hline $\mathrm{V} 2$ & 1 & 1 & 2 & 4 \\
\hline V3 & $1 / 3$ & $1 / 2$ & 1 & 3 \\
\hline V4 & $1 / 5$ & $1 / 4$ & $1 / 3$ & 1 \\
\hline
\end{tabular}

The normalized matrix is obtained by dividing the cell value with the column total. The table below gives the normalized matrix for DI pipes with respect to Quality.

\section{Normalized Matrix}

\begin{tabular}{|l|l|l|l|}
\hline 0.395 & 0.364 & 0.474 & 0.385 \\
\hline 0.395 & 0.364 & 0.316 & 0.308 \\
\hline 0.132 & 0.182 & 0.158 & 0.231 \\
\hline 0.079 & 0.091 & 0.053 & 0.077 \\
\hline
\end{tabular}

From the normalized table, calculate row total and row average which is shown in the table below. 


Row
Total
\begin{tabular}{|l|l|}
\hline 1.617 \\
\hline 1.382 \\
\hline 0.702 \\
\hline 0.299 \\
\hline
\end{tabular}$\quad$\begin{tabular}{ll} 
Scores \\
\hline 0.404 \\
\hline 0.345 \\
\hline 0.176 \\
\hline 0.075 \\
\hline
\end{tabular}

Step 3- Consistency Check

Consistency Measure is being calculated by matrix multiplication (first row of normalized matrix with column of averages) and then dividing the resultant value by the corresponding average value.

Consistency Index $(\mathrm{CI})$ is obtained from the formula $\lambda \max -n n-1$

Where $\mathrm{n}=$ number of vendors

$\lambda \max =$ average of Consistency Measure

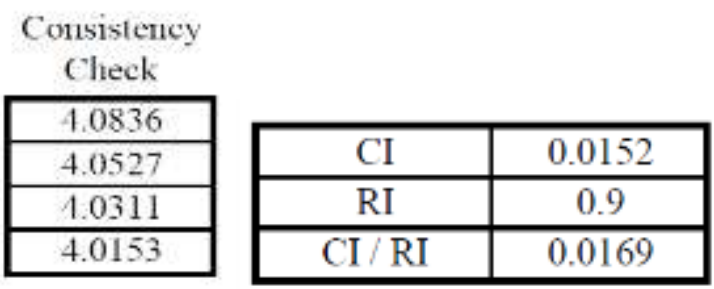

The consistency index (CI) is 0.0152 . Since the $\mathrm{CI}$ is $<0.1$.

Similar analysis is done for

\section{Response}

The pair-wise comparisons of the vendors with respect to Response criteria are given below with the respective normalized matrix, scores and consistency index.

Pairwise Comparison of DI Vendors based on Response

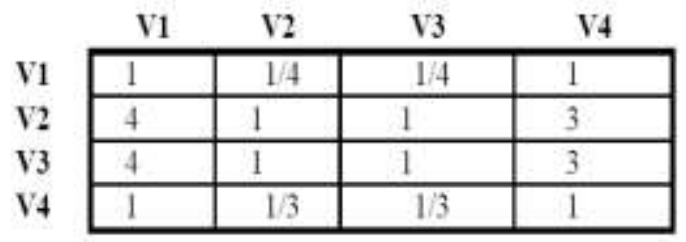

Normalized Matrix

\begin{tabular}{|l|l|l|l|}
\hline 0.100 & 0.097 & 0.097 & 0.125 \\
\hline 0.400 & 0.387 & 0.387 & 0.375 \\
\hline 0.400 & 0.387 & 0.387 & 0.375 \\
\hline 0.100 & 0.129 & 0.129 & 0.125 \\
\hline
\end{tabular}

\begin{tabular}{|c|c|c|}
\hline $\begin{array}{l}\text { Row } \\
\text { Total }\end{array}$ & Scores & $\begin{array}{c}\text { Consistency } \\
\text { Check }\end{array}$ \\
\hline 0.419 & 0.105 & 4.0048 \\
\hline 1.549 & 0.387 & 4.0161 \\
\hline 1.549 & 0.387 & 4.0161 \\
\hline 0.483 & 0.121 & 4.0045 \\
\hline
\end{tabular}

\begin{tabular}{|c|r|}
\hline $\mathrm{CI}$ & 0.0035 \\
\hline $\mathrm{RI}$ & 09 \\
\hline $\mathrm{CI} / \mathrm{RI}$ & 0.0038 \\
\hline
\end{tabular}

\section{Price}

The pair-wise comparisons of the vendors with respect to Price criteria are given below with the respective normalized matrix, scores and consistency index.

Pairwise Comparison of DI Vendors based on Price Competitiveness

\begin{tabular}{l|l|l|l|l|}
\multicolumn{1}{c}{ V1 } & \multicolumn{1}{c}{ V2 } & \multicolumn{1}{c}{ V3 } & \multicolumn{1}{c|}{ V4 } \\
\cline { 2 - 5 } V1 & 1 & $1 / 2$ & 1 & 2 \\
\cline { 2 - 5 } V2 & 2 & 1 & 1 & 2 \\
\cline { 2 - 5 } V3 & 1 & 1 & 2 \\
\cline { 2 - 5 } V4 & $1 / 2$ & $1 / 2$ & 1 \\
\cline { 2 - 5 } & & &
\end{tabular}

Normalized Matrix

\begin{tabular}{|l|l|l|l|}
\hline 0.222 & 0.167 & 0.286 & 0.286 \\
\hline 0.444 & 0.333 & 0.286 & 0.286 \\
\hline 0.222 & 0.333 & 0.286 & 0.286 \\
\hline 0.111 & 0.167 & 0.143 & 0.143 \\
\hline
\end{tabular}

Row
Total
\begin{tabular}{|l|l|}
\hline 0.960 \\
\hline 1.349 \\
\hline 1.127 \\
\hline 0.563 \\
\hline
\end{tabular}$\quad$\begin{tabular}{l|} 
Scores \\
\hline 0.240 \\
\hline 0.337 \\
\hline 0.282 \\
\hline 0.141 \\
\hline
\end{tabular}

Consistency Check

\begin{tabular}{|l|}
\hline 4.0496 \\
\hline 4.0941 \\
\hline 4.0493 \\
\hline 4.0493 \\
\hline
\end{tabular}

\begin{tabular}{|c|c|}
\hline CI & 0.0202 \\
\hline RI & 0.9 \\
\hline $\mathrm{CI} / \mathrm{RI}$ & 0.0224 \\
\hline
\end{tabular}

\section{Delivery}

The pair-wise comparisons of the vendors with respect to Delivery criteria are given below with the 
respective normalized matrix, scores and consistency index.

Pairwise Comparison of DI Vendors based on Delivery

\begin{tabular}{l|l|l|l|l|}
\multicolumn{1}{c}{ V1 } & \multicolumn{1}{c}{ V2 } & \multicolumn{1}{c}{ V3 } & V4 \\
\cline { 2 - 5 } V1 & 1 & $1 / 5$ & $1 / 4$ & $1 / 2$ \\
\cline { 2 - 5 } V2 & 5 & 1 & 1 & 2 \\
\cline { 2 - 5 } V3 & 4 & 1 & 1 & 3 \\
\cline { 2 - 5 } V4 & 2 & $1 / 2$ & $1 / 3$ & 1 \\
\cline { 2 - 5 } & & &
\end{tabular}

Normalized Matrix

\begin{tabular}{|l|l|l|l|}
\hline 0.083 & 0.074 & 0.097 & 0.077 \\
\hline 0.417 & 0.370 & 0.387 & 0.308 \\
\hline 0.333 & 0.370 & 0.387 & 0.462 \\
\hline 0.167 & 0.185 & 0.129 & 0.154 \\
\hline
\end{tabular}

\begin{tabular}{|c|c|c|}
\hline $\begin{array}{l}\text { Row } \\
\text { Total }\end{array}$ & Scores & $\begin{array}{c}\text { Consistency } \\
\text { Check }\end{array}$ \\
\hline 0.331 & 0.083 & 4.0257 \\
\hline 1.482 & 0.370 & 4.0215 \\
\hline 1.552 & 0.388 & 4.0344 \\
\hline 0.635 & 0.159 & 4.0258 \\
\hline
\end{tabular}

\begin{tabular}{|c|c|}
\hline $\mathrm{CI}$ & 0.0089 \\
\hline $\mathrm{RI}$ & 0.9 \\
\hline $\mathrm{CI} / \mathrm{RI}$ & 0.0099 \\
\hline
\end{tabular}

\section{Credit Period}

The pair-wise comparisons of the vendors with respect to Credit criteria are given below with the respective normalized matrix, scores and consistency index.

Pairwise Comparison of DI Vendors based on Credit Period

\begin{tabular}{|c|c|c|c|}
\hline V1 & V2 & V3 & $V_{4}$ \\
\hline V1 & $1 / 4$ & $1 / 6$ & $1 / 2$ \\
\hline $\mathrm{V}_{2}$ & 1 & $1 / 3$ & 2 \\
\hline V3 & 3 & 1 & 4 \\
\hline $\mathrm{V} 4$ & $1 / 2$ & $1 / 4$ & 1 \\
\hline
\end{tabular}

Normalized Matrix

\begin{tabular}{|l|l|l|l|}
\hline 0.077 & 0.053 & 0.095 & 0.067 \\
\hline 0.308 & 0.211 & 0.190 & 0.267 \\
\hline 0.462 & 0.632 & 0.571 & 0.533 \\
\hline 0.154 & 0.105 & 0.143 & 0.133 \\
\hline
\end{tabular}

\begin{tabular}{|l|}
$\begin{array}{l}\text { Row } \\
\text { Total }\end{array}$ \\
\begin{tabular}{|l|}
\hline 0.291 \\
\hline 0.975 \\
\hline 2.198 \\
\hline 0.535 \\
\hline
\end{tabular}
\end{tabular}

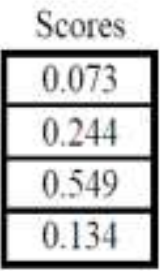

Consistency Check

\begin{tabular}{|l|}
\hline 4.0118 \\
\hline 4.0441 \\
\hline 4.1012 \\
\hline 4.0265 \\
\hline
\end{tabular}

\begin{tabular}{|c|c|}
\hline $\mathrm{CI}$ & 0.01529 \\
\hline $\mathrm{RI}$ & 0.9 \\
\hline $\mathrm{CI} / \mathrm{RI}$ & 0.01699 \\
\hline
\end{tabular}

The pair-wise comparison of all the selection criteria, the normalized matrix, scores and the consistency index are given in the table below:

\section{Pair-wise Comparison of Selection Criteria}

\begin{tabular}{|c|c|c|c|c|c|}
\cline { 2 - 6 } \multicolumn{1}{c|}{} & Quality & Delivery & $\begin{array}{c}\text { Price } \\
\text { Competitiveness }\end{array}$ & Respocse & $\begin{array}{c}\text { Credit } \\
\text { Penod }\end{array}$ \\
\hline Quality & 1 & 1 & 1 & 5 & 5 \\
\hline Delivery & 1 & 1 & 3 & 5 & 3 \\
\hline $\begin{array}{c}\text { Price } \\
\text { Competitiveness }\end{array}$ & 1 & $1 / 3$ & 1 & 3 & 5 \\
\hline Response & $1 / 5$ & $1 / 5$ & $1 / 3$ & 1 & $1 / 3$ \\
\hline Credit Penod & $1 / 5$ & $1 / 3$ & $1 / 5$ & 3 & 1 \\
\hline
\end{tabular}

Nomalized Matrix

\begin{tabular}{|l|l|l|l|l|}
\hline 0.294 & 0.349 & 0.181 & 0.294 & 0.349 \\
\hline 0.294 & 0.349 & 0.542 & 0.294 & 0.209 \\
\hline 0.294 & 0.116 & 0.181 & 0.176 & 0.349 \\
\hline 0.059 & 0.070 & 0.060 & 0.059 & 0.023 \\
\hline 0.059 & 0.116 & 0.036 & 0.176 & 0.070 \\
\hline
\end{tabular}
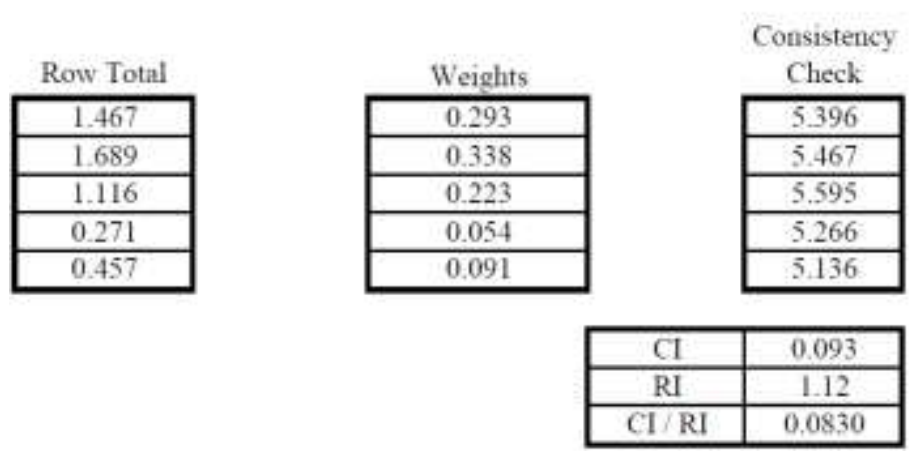
Final Score Matrix

Price

\begin{tabular}{l|c|c|c|c|c|}
\multicolumn{5}{c}{} & \multicolumn{5}{c}{ Quality } & \multicolumn{1}{c}{ Delivery } & \multicolumn{2}{c|}{ Competitiveness } & Response & \multicolumn{1}{c|}{ Credit Period } \\
\cline { 2 - 6 } V1 & 0.404 & 0.083 & 0.240 & 0.105 & 0.073 \\
\cline { 2 - 6 } V2 & 0.346 & 0.371 & 0.337 & 0.388 & 0.244 \\
\cline { 2 - 6 } V3 & 0.176 & 0.388 & 0.282 & 0.388 & 0.549 \\
\cline { 2 - 6 } V4 & 0.075 & 0.159 & 0.141 & 0.121 & 0.134 \\
\cline { 2 - 6 }
\end{tabular}

The Final Scores for each vendor is obtained by matrix multiplying the weights of criteria and scores of vendors rated based on each criterion.

Weights of Selection Criteria

\begin{tabular}{|l|}
\hline 0.293 \\
\hline 0.338 \\
\hline 0.223 \\
\hline 0.054 \\
\hline 0.091 \\
\hline
\end{tabular}

Ranking of Vendors

\begin{tabular}{|l|l|l|}
\hline 0.2125 & 3 & V1 \\
\hline 0.3452 & 1 & V2 \\
\hline 0.3168 & 2 & V3 \\
\hline 0.1258 & 4 & V4 \\
\hline
\end{tabular}

Thus, we find that it is possible to rate the vendors using multi-criteria using Analytical Hierarchical Processing. The Vendor V2 is top in the rating followed by V3, V1 and V4.

\section{Conclusion}

The proposed Vendor Rating System has reduced some amount of subjectivity in evaluating the performance of vendors, but it is not completely free of subjectivity. This rating system uses only AHP methodology. However, this method can be coupled with techniques like Data Envelopment Analysis (DEA), Muti-Objective Linear Programming etc., in order to increase the efficiency of output. This system considers only major selection criterion for rating the vendors. However, there are various other criterion like financial prudence, brand image, etc., available for rating the vendors. The feedback may be given to vendors based on their ranking, obtained through this system. This system is found to be useful for vendor development and interaction.

\section{References}

[1] Akshay A. Patil, Prof.Madhav, B. Kumthekar, "Supplier Evaluation and selection methods in construction industry", International Research Journal of Engineering and Technology (IRJET), Volume: 03 Issue: 06, June-2016.

[2] Ao Chen. Reverse logistics supplier selection model research in the supply chain of closed loop [J]. Industrial technology economy, 2007 (7): 44-47.

[3] Awino Z. B. (2002) "Purchasing and Supply Chain Strategy: Benefits, Barriers and Bridges" An Independent Conceptual Study Paper in Strategic Management, School of Business, University of Nairobi September 2002

[4] Beamon, B., Measuring supply chain performance. International Journal of Operations and Production Management 19 (3), 275-292(1999)

[5] Cebeci U. Multi-criteria supplier selection using fuzzy AHP [J]. Logistics Information Management, 2003 (6):382-394.

[6] ChuanXu Wang. The third party logistics service supplier's selection model based on association and the structure of the feedback [J]. Shanghai: Shanghai Maritime University, 2004, (3): 43-46.

[7] Choy KL, Lee WB., on the development of a case based supplier management tool for multinational manufacturers. Measuring Business Excellence 2002; 6(1):pp.15 - 22, 2002

[8] Cox A. (1999). "Power, Value and SCM". Supply Chain Management: An International Journal. 4(4) 167-175

[9] Farzad Tahriri; M. Rasid Osman; Aidy Ali; Rosnah Mohd Yusuff; Alireza Esfandiary, "AHP Approach For Supplier Evaluation And Selection In A Steel Manufacturing Company", Journal of Industrial Engineering And Management, Vol. 01 (02), Pp. 54 - 76.

[10] Handfield, R.B. and Nichols, E.L. Introduction to Supply Chain Management. , Prentice Hall, USA(1999)

[11] Harps L. H. (2000). "The Haves and the Have Nots": Supply Chain Practices for the New Millenium: Inbound Logistics Journal. $75-114$ 
[12] B. Kingsman, S. Yahya, "Vendor rating for entrepreneur development programme: a case study using analytical hierarchy process method", Journal of the Operational Research Society, Vol. 50 (1999), Pg. No. $916-930$.

[13] K. Krishna Veni, R. Rajesh, S. Pugazhendhi, "Development of Decision making model using Integrated AHP and DEA for Vendor Selection", International Conference on Modelling Optimization and Computing, Procedia Engineering, Elsevier Publ., Vol 38 (2012), Pg. No. 3702 - 3708.

[14] 5. Kurian John, Vinod Yeldho Baby, Georgekutty S.Mangalathu, "Vendor Evaluation And Rating Using Analytical Hierarchy Process", International Journal Of Engineering Science And Innovative Technology (IJESIT), Volume 2, Issue 3, May 2013, PP.447.

[15] LiJiang Zhao, XianYing Xu, YiBo Li. The fuzzy decision-making method of the third party logistics supplier selection [J]. Logistics technology, 2003 (9): 35 to 44.

[16] Stanley E. G. and Gregory M. M. (2001) "Achieving World Class Supply Chain Alignment: Benefits, Barriers and Bridges" A Compiled Research Report.

[17] Vera R, Pullman ME.,An analysis of the supplier selection process. Omega, International Journal of Management Science 1998 ; 26 (6): pp739-50, 1998

[18] Yao Chen, Joe Zhu. DEA models for identifying critical performance measures [J].Annals ofOerationsResearch, 2003(11): 225-244.

[19] KaiYuan Liu, Rong Wang, BaoHui Jin. A fuzzy assessment model of supplier and its realization $[\mathrm{J}]$. Journal of Wuhan University of Technology (traffic science and engineering edition), 2004 (3): 420423.

[20] ChengWu Fang, XunPing Lei. Use of fuzzy decision method in logistics supplier selection [J]. Journal of Anhui University of Technology (social sciences), 2005 (1):4647.

[21] Melvin Alexander, "Decision Making Using the Analytic Hierarchy Process (AHP) And SAS/IML®",

Http://Analytics.Ncsu.Edu/Sesug/2012/SD04.Pdf

[22] MinTun Li. The third party logistics supplier fuzzy comprehensive evaluation of supply chain management [J]. Journal of Ningbo College of Vocational and Technical, 2006 (2): 99-101.

[23] YiXin Shi, DanSong zhang. The third party logistical service contractor selection model based on the fuzzy comprehensive evaluation method [J]. Logistics technology, 2006 (9): 5-8.

[24] Rong Chen. Application of principal component analysis method in evaluation of comprehensive strength of logistics supplier [J]. Logistics technology, 2007 (2): 42-44.

[25] Samuel H. Huang, Harshal Keskar, "Comprehensive and Configurable Metrics for Supplier Selection", International Journal of Production Economics, Issue 105, PP. 510 $-523$.

[26] Chang Seong Ko. A genetic algorithm approach to develo-ping the multi-echelon reverse logistics network for prod-uct returns [J]. The International Journal of Management Science, 2000(10): 56-69.

[27] Supakit Laksanasiri, Naprud Paisansin, Pornthep Anussornnitisarn, "Analytic Hierarchy Process Method For Selecting Supplier In Automotive Business", Joint International Conference, Bari, Italy, May 2015.

[28] YongRui Duan, Peng Tian, WeiPing Zhang. Based on the DEA method to select suppliers [J]. Industrial engineering and management, 2004 (2): 71-74. 